\title{
How Collective Intelligent Decisions in Public Policymaking are Made: Case Study of Participatory Budgeting in Kraków
}

\author{
RafałOlszowski ${ }^{1,2 *}$
}

1 AGH University of Science and Technology, Faculty of Humanities; Gramatyka 8a, 30-071 Kraków, Poland;rolszowski@agh.edu.pl

2 Massachusetts Institute of Technology, Center for Collective Intelligence; 245 First Street, E94, Cambridge, MA 02142, USA; rafalols@mit.edu

* Correspondence: $\underline{\text { rafalols@mit.edu }}$

\begin{abstract}
:
E-participation research still lacks analytical models explaining how collective decisions are made. One of the most promising approaches to the study of online projects that may reveal new aspects of decision-making is to analyze the cognitive processes related to collective intelligence emerging in these projects. Therefore, the aim of this study was to prepare a framework for evaluating in a single e-participation project the processes that influence making decisions that may affect public policy. A vast literature review, and case study method based on semi-structured interviews were employed to evaluate a sample participatory budgeting initiative, Civic Budget of the City of Kraków. The qualitative research applied grounded theory approach to develop an evaluation framework, that can be used in future studies. Data analysis proved that most of the cognitive processes in analyzed case are working relatively well, with one notable exception: the process of collective memory works only to a very limited extent. The identified problem is especially important, as memory-related processes are considered crucial for the functioning of the entire intelligence system.
\end{abstract}

Keywords: collective intelligence, decision-making, policymaking, public policy, e-participation, participatory budgeting, cognitive systems, group cognition.

\section{Introduction}

Open, inclusive and participatory policymaking has become a global challenge in terms of achieving the goals of sustainable society. Shaping public policies is an extremely complex process occurring in changing environments, being influenced by different interests, and affecting the three pillars of sustainable development: social relations, economy, and the environment. In the modern world, with its increasing complexity, uncertainty and social unrest, it is becoming ever more important to ensure that this process adequately deals with the real challenges and that it constantly improves its model [1].

Due to the widespread use of information technology and network communication, we can observe the trend of implementing ICT tools when supporting public decision making and optimising policy planning $[2,3]$, analysing large amounts of social data to detect patterns and abnormalities $[4,5]$, using dynamic models for learning, adaptation and forecasting of policy formulation [2, 6], real-time continuous policy monitoring [7, 8], as well as participating in online public debates and consultations $[1,9]$. This contributes to the fact that nowadays public governance reaches an increasingly wide range of stakeholders who are more and more involved in the whole policy-cycle: not only in agenda-setting, but in designing the policies, adopting them (through the increasing role of self-regulation), and implementing them. Therefore, e-participation, defined as the use of information technologies to engage in discourse among citizens and between citizens and elected or appointed officials over public policy issues [10], serves as much more than a communication channel between the citizens and public administration. 
Governments around the world are experimenting with e-participation tools to enhance citizen engagement in developing policy, improving service delivery, opening public organisations, as well as gathering distributed wisdom and know-how of diverse participants to improve public decision-making [11, 12]. Several studies indicated the possible positive effects of online citizen participation in directly influencing government decisions, but also in enhancing transparency and developing citizenship [9, 13, 14]. E-participation platforms, where citizens can propose, discuss, give feedback, and vote for initiatives aimed to address a wide range of issues and problems, have been significantly improved in recent years, allowing their users to move beyond the role of the information receiver, and engage directly in policymaking [15]. The possible impact of e-participation on development of fairer and more balanced society was demonstrated in many studies, including Gil et al. [15] and Cantador et al. [16], where legitimacy, effectiveness and efficiency of public policies, as well as the development of an active citizenship were evaluated. The notable cases of open policymaking supported by ICT technologies include: collaborative lawmaking conducted in Brazil [17]; the Icelandic constitutional process between 2010 and 2013 [18]; collaborative consensus-mining using artificial intelligence in the vTaiwan project [19]; urban policymaking and citizen empowerment in Decide Madrid [20], municipal open innovation in the city of Reykyavik [21]; crowdsourcing policy proposals for mitigating political corruption in Estonia [22]; or the Evidence Checks, where British citizens are invited to provide online comments on the rigor of evidence on which public policy is based [23].

Despite the hopes, empirical analyses show that many e-participation initiatives have failed to make a significant impact on public policymaking [24, 25, 26, 27]. The observations resulting from the analyzed phenomena show that achieving engagement and meaningful collaboration through online e-participation projects requires a better understanding of what restrains governments and citizens from being able to effectively collaborate, both online and offline [20]. E-participation research has outlined a several success and failure factors, but still lacks analytical models explaining how these factors influence and cause public decisions to be made. Identified barriers to effective citizen e-participation include: technological advancements and data management [28, 29], low public knowledge of the issues treated, poor provision of data, participants' lack of representativeness, shortage of political support, failure to achieve impact on the decision-making processes, or the regulatory constraints [10, 20, 24, 30]. All of this can cause various tensions and conflicts, disappointment and reluctance to engage in future participation [3, 31]. Awareness of these problems was an incentive to search for new analytical approaches towards discovering the reasons for failure or success of participatory policymaking projects.

One of the most promising approaches to the study of online projects that may reveal new aspects of open policymaking is to analyze the manifestations of collective intelligence (CI) emerging in these projects. The phenomenon of CI, which is understood as an ability of a particular collective to solve problems, mainly through gathering data, generating ideas and making decisions, has been the subject of interest of many scientific disciplines in recent years. Intelligence that appears in online communities is understood as a form of distributed ability, which arises from the collaboration and competition between many individuals in cyberspace [32]. From the very beginning, the peculiarity of these studies is the assumption of a kind of "collective mind" and the use of terminology derived from cognitive psychology to describe it $[33,34,35]$. The analysis of group cognition processes [36], or plainly speaking the "collective way of thinking", as a proper way to understand the different aspects of CI was proposed by Heylighen [34] Malone [35], Mulgan [37] and others [38, 39, 40].However, a systematic review of the existing literature proved that no specific method of evaluating CI in online policymaking projects through the empirical analysis of the group cognition has been proposed so far.

Therefore, the aim of this study is to prepare a framework of collective intelligence in policymaking, in particular, these intelligence processes that influence decision-making that may affect public policy. The main research questions are stated as: 
- What cognitive processes are related to collective decisions in the field of public policymaking?

- Can we identify the group cognitive processes in a single e-participation project?

In the first stage of the conducted study, a vast literature review was conducted, aimed at identifying the methods of CI research used so far in e-participatory policymaking, and to define a theoretical basis referring to collective cognitive processes (described in Section 2). This defined preliminary framework was further developed with the use of the constructivist grounded theory approach, as proposed by Charmaz [41]. First, an initial interview was conducted to evaluate the preliminary framework and data collection protocol for their credibility and confirmability. Then, a participatory budgeting project - Civic Budget of the City of Kraków - was selected for an in-depth study based on semi-structured interviews. As a result of the sampling, 20 respondents met the inclusion criteria, with whom 20 interviews were subsequently conducted. Data collection and analysis (theoretical sampling) were conducted simultaneously, therefore the theory was grounded in the experiences of the participants (Section 3). In the final stage of the presented study, a framework outline was populated with the collected experiences and the extended references to relevant literature, to enhance the internal validity and theoretical quality of the research. The results of this work are presented inSection 4 . The final sections of the article summarize the key conclusions and provide prospects for future research.

\section{Literature Review. Preliminary Evaluation Framework}

Although the idea of community involvement in co-creation of public policies was proposed by Elinor Ostrom long before the Internet age [42], the transition from a traditional model of citizen as customer [43] to the expected "We-Government" (citizen as partner) [44] has accelerated significantly in recent years. Regarding the 2030 Agenda for Sustainable Development, approved by all United Nations Member States in 2015, responsive, inclusive, participatory and representative decision-making at all levels is one of the adopted strategic goals [45]. The role of governments has substantially changed, and the emergence of new and complex social problems requires looking for new ways to collaborate in making public decisions with non-governmental actors. This means opening policymaking tasks to public participation, in the spirit of transparent governance institutionalised by the Open Government Initiative [46, 47, 48]. This process, fuelled by the participatory democracy theories $[49,50]$, as well as the concept of deliberative democracy [51], finds its practical expression in a paradigm shift towards New Public Governance $[52,53]$ or collaborative governance $[54,55]$, where policy issues are addressed by networks of governmental and non-governmental actors. According to Capella, deliberating groups can be effective in advancing the epistemic bases for good decisions and for enhancing the quality of decisions [...] concerning public issues, however, there is a need to find a better way to define how collective intelligent decisions are made, and what affects the quality of the e-participation projects' results [56].

To verify how the manifestations of collective intelligence in online policymaking projects have been studied so far, a semi-systematic literature review, supported by RAMESES standards [57] and following H. Snyder guidelines [58], was conducted (see more details: Appendix A).The refined list of 75 peer-reviewed scientific articles were the subject of a narrative review and meta-analysis of the content. As a result, 15 methods and strategies for studying $\mathrm{CI}$ in public policymaking projects were identified. Each of the analysed texts was assigned a min. of 1 and a max. of 4 methods and strategies used (listed below from the most to the least frequent):

Table 1.Methods and strategies for studying $\mathrm{CI}$ in public policymaking in the reviewed scientific literature.

Method or strategy No. of references




\begin{tabular}{cl}
\hline Analysis of organizational structure/design & 23 \\
Analysis of created values & 18 \\
Analysis of participation process & 14 \\
Analysis of participants' behavior & 12 \\
Analysis of collaboration model & 11 \\
Analysis of participants' motivations & 10 \\
Analysis of communication model & 10 \\
Analysis of innovation & 8 \\
Analysis of decision-making process & 7 \\
Categorization of the implemented projects & 6 \\
State-of-the-art review & 4 \\
Analysis of the impact on policymaking & 3 \\
Analysis of platform usability & 2 \\
Analysis of the impact of AI algorithms & 2 \\
Analysis of organizational learning & 1 \\
\hline
\end{tabular}

The conducted review revealed the lack of a systematic method of evaluating CI in the public sphere, which treated e-participation projects as systems of group cognition and allowed the study of group cognitive processes. Therefore, to answer the research questions posed, it was necessary to prepare a new evaluation framework, based on the relevant theoretical and empirical knowledge. Following the recommendations of R. Torraco [59], a method of creating such a framework requires an integrative literature review. This involves outlining a preliminary theory and setting it against the background of domain knowledge. At this point, it was decided that in the next stages of research, the grounded theory method would be employed, thus the preliminary theory was to be grounded through in-depth qualitative analysis of the selected case study. After this empirical verification, it was to be supplemented with references to the scientific literature, describing results of empirical research on collective intelligence.

For the purpose of creating the preliminary theory basis, the Web of Science database was searched again, using the keywords "group cognition" or "collective cognition" and "framework" or "theoretical framework". As a result, the refined list of 15scientific articles were obtained (see more details: Appendix A). The qualitative analysis of these results proved again, that no framework for evaluation of group cognitive processes in policymaking existed before in the reviewed literature. When selecting the theoretical basis to be farther developed, its potential complementarity and compatibility with the previous research on online collective intelligence was the guiding principle . After a qualitative analysis of the results obtained, it was decided to choose as the guiding theory the Multiple, Interacting Levels of Cognitive Systems (MILCS) perspective, as proposed by R. Goldstone and G. Theiner [36].

The MILCS framework presents cognitive psychology as the study of how people focus attention, perceive, learn, structure, store, think about information, solve problems and make decisions. It adopts R. Sternberg's definition that cognitivism is the belief that much of human behavior can be understood in terms of how people think - the study of how people mentally represent and process information. As such, it includes within its domain mental abilities such as perception, learning, memory, reasoning, problem solving, and decision making [60]. At the same time, MILCS focuses on mechanisms that allow systems to engage in flexible, adaptive behavior [36] and adopts the perspective of group cognition, where certain kinds of collective systems are able to achieve functionalities that are relevant for cognitive processes primarily considered as related to the individuals. The main cognitive processes are perception, attention, memory, problem solving, and decision making [36]. Such a divi- 
sion is derived from one of the earliest definitions presented in the first textbook on cognitive psychology published in 1967, which according to Neisser states cognition is those processes by which the sensory input is transformed, reduced, elaborated, stored, recovered, and used [61]. A cognitive, "thinking" system, therefore, refers to many partially overlapping notions: increasingly sophisticated memory, attention, planning, problem solving, search, communication, decision making in a collective, which have increasing flexibility in the methods that they can deploy to achieve their goals despite environmental obstacles [36]. These processes concern both the fluid or crystallized intelligence, as described by Cattell [62]: the fluid intelligence appears, when a cognitive system solves problems with the use of deduction, logic, and inference, depending only minimally on prior learning, but the "thinking" mechanism can also be based on the learned procedures and gathered (crystallized) knowledge, precipitated out of experience resulting from the prior application of fluid ability [63]. The distributed intelligence refers to cognitive processes that are stretched across individuals and their different components (mind, body, activity), as well as culturally organized settings, including groups and institutions. Distributed cognition thus refers to an emergent phenomenon that cannot be traced simply to individual minds, but rather to the interaction between those minds and between them and their constructed environment (which plays the role of extending their cognitive capacities) [64]. Such a system can contain several forms of interacting units: not only humans, but also communication nodes, artificial agents, sub-groups, technical infrastructure $[34,36]$. MILCS presents the cognitive reality as a meta-system, where numerous, independent cognitive systems operate, often consisting of sub-systems. This is in line with the approach specific to CI researchers, who see manifestations of intelligence in both large crowds and small communities.

A particularly interesting element of the MILCS framework is the rejection of a "zero-sum" perspective of the group cognition presented by Huebner [65]. Indicating that the collective system exhibits a different level of intelligence than the sum of its individual parts, dependent on many factors such as: diffusion, preferential attachment, competitive specialization, positive feedback, negative feedback, small-world network, scale-free network, back propagation, reinforcement learning, and multi-level deep learning [36], therefore establishing the irreducibility of group mentality. MILCS provides evidence, that " $\mathrm{z}$ ero-sum" perspective loses its plausibility when we consider the dynamics of largescale social systems that contain multiple people and an environment that facilitates their interactions $[66,67,68]$. In such systems cognition arises from the interactions between all parts, especially when its structure is based on a decentralized network. This position is consistent with the results of empirical research developed by A. Woolley et al., which show that the collective intelligence of a specific group can be measured, and has a computable value which is often different than the sum of the intelligence of its members [69]. Collective cognitive processes are also conditioned by factors that can be managed, such as the structure of the group, the way its work is organized, and the technical means at its disposal [70]. Therefore, we can influence the development of the intelligence of collectives by creating optimal conditions for their operation, influencing their composition, principles, communication methods, work cycle, self-organization, as well as various technical measures to improve their operation [71]. Information in these kind of networks is propagated selectively, depending on its utility, novelty, coherence, simplicity, expressivity, authority etc. [70].

The way cognitive processes are carried out differs greatly depending on the type of collective. The distinction between communities or organizations based on personal relationships, and large moblike structures, leads D. Andler to describe "thick" collective cognitive processes, being a feature of communities united in a common spirit [...], constantly coordinated and recalibrating their mutual expectations, blending into a "we" capable of we-thoughts, we-intentions, we-actions, culturally transmitting their beliefs and practices, and exhibiting similarity to the individual cognitive systems [39]. Previous research on CI confirms, that these kinds of processes lead to the emergence of CI, not in every situation, but one in which a specific group is to achieve a specifically defined goal, e.g. to make a decision, which is preceded by drawing conclusions from data, exchanging information, 
debating, enabling interaction between people (or computers and people) [56]. In contrast, Andler describes also the "thin" collective cognitive processes, in which individual agents, far from deliberating or exchanging information and arguments, simply provide their own conclusions, which are then fed to some aggregating algorithm or mechanism. The possibility of getting "intelligent" results coming from incoherent crowds was highlighted by Surowiecki, who evoked many examples on surprising "order coming out of chaos" in his famous work The Wisdom of the Crowds [72]. Andler completes this statement claiming that social organizations benefit from the absence of certain individualistic constraints that are traditionally thought to foster excellence in cognitive tasks [39]. This issue was further developed by Hong and Page, who made the crowd's problem-solving abilities dependent on the level of its cognitive diversity: large, diverse crowds tend to produce negatively correlated predictions, [that can] produce better aggregate outcomes. If two predictions are negatively correlated, when one tends to be high, the other tends to be low, making the average more accurate [73]. In most cases, however, we are not dealing with a pure form of any of the "thick" or "thin" models, but with a combination of both: classical thick procedures can be simplified so as to limit interactions to a more or less restricted set, and symmetrically thin procedures can be enriched so as to allow "thicker" information to be transmitted and aggregated [39].

Based on the theoretical basis outlined above, the initial data collection protocol was prepared and the following stages of study were planned.

\section{Case Study: Civic Budget in Kraków}

\subsection{Methodology}

The next stage of the research was the development of preliminary theoretical basis described above with the use of the grounded theory method, following the directions of Charmaz [41] and Corbin \& Strauss [74]. A singlecase analysis was chosen for this purpose. Since a singlecase method is considered appropriate for an in-depth analysis of complex phenomena [75,76], it was found to be well suited for tracking collective cognitive processes in policymaking. As Yin points out, case study analysis is considered suitable to describe a phenomenon, build theory or test theoretical concepts or relationships, or a combination of all three[77, 78].Dyer and Wilkins argue that findings from a single study can be more useful than an approach in which multiple studies are used for data collection as proposed by Eisenhardt and Gable. A singlecase study prioritizes richness of data over the ability to compare multiple instances and wide explanatory power $[77,79,80,81]$.

As for the case selection criteria, the general assumption was to analyze a representative e-participation initiative, which at the same time was being affected by significant difficulties whose nature could be revealed by analyzing collective cognitive processes. As part of the selection procedure, a preliminary evaluation to narrow down the list of the relevant cases was made. The criteria for selecting the cases to be shortlisted were: satisfaction of the significant features of the online policymaking project; importance of the public issues raised; clearly visible problems in achieving the project goals; and finally the place of implementation. 6 projects were implemented in Polish communities, 2 implemented in Central and Eastern European Communities other than Poland, and 2 implemented in selected Western European communities. The final case for in-depth qualitative research selected from this list was a participatory budgeting project Budżet Obywatelski Miasta Krakowa, translated as Civic Budget of the City of Kraków (CBCK).In the model of participatory budgeting (PB) widely implemented in many countries, where citizens of a given municipality gain influence on its policies in the field of public investments, social activities, and cultural activities, there exists a large group of notable e-participation projects (see i.e. [51, 82, 83, 84]). We can describe PB as a policymaking process during which the citizens discuss and negotiate the issue of distribution of public funds [85]. Participants of the process engage in submitting proposals, conducting deliberation, and making decisions about how public resources ought to be allocated on investment ventures, social, and cultural initiatives. 
Although Kraków stands out from other Polish cities because of its recognition as a tourist destination and an outsourcing business center, the Civic Budget of the City of Kraków project does not differ in its scope from numerous similar initiatives, conducted in the municipalities of Central - Eastern Europe. The comparative analysis shows that the model of participatory budgeting (PB) in Poland is similar to the model present in other countries in the region, apart from one important element: the Polish projects were based primarily on Internet voting from the very beginning of their existence, which led to a greater participation than in other countries in the region [86]. This element was further strengthened in 2020: due to the situation related to the global coronavirus pandemic, virtually all activities were transferred to the Internet. This applied not only to voting, but also to brainstorming and evaluation processes. This circumstance allows the project to be classified as a fully e-participatory initiative. The overall picture of PB in Kraków compared to other Polish cities proves that its method of implementation and its community's activities do not set it apart it significantly. However, the review of circumstances related to its conduct, especially low participation turnout and the problems in establishing community ties, indicate that Kraków's results are among the weakest in the medium and large cities in Poland [87]. For this reason, this case was considered as the most promising to be evaluated in the course of further work, and an attempt to identify the causes of the related problems was made.

To ensure data trianglulation, two research techniques were used in studying the selected case: semi-structured interviews, and examining documents obtained through desk research. The interview agenda and questions were based on a previously developed theoretical framework. A pilot case study (trial interview) was initially conducted with a senior project manager working in the participatory budgeting field in another municipality. The main aim of this pilot was to evaluate the preliminary framework and data collection protocol for their credibility and confirmability. The improved agenda provided the basis for the interviews that were the primary way to collect case study data. The sampling for interviews was conducted through e-mails and telephone calls. The inclusion criteria focused on the experience gained by the participants in previous editions of CBCK in various roles: projects managers, Ambassadors of Local Participation, public employees, evaluators, representatives of NGOs. Convenience sampling was used, which is a common type of nonprobability sampling technique [88] used in qualitative research of similar kinds [89]. As a result of the sampling, 20 respondents met the inclusion criteria, with whom 20 semi-structured interviews were conducted, both with the use of teleconference software and face-to-face meetings. All participants were informed that their anonymity would be guaranteed. The interview consisted of open-ended questions and the procedure was semi-structured. Data collection and analysis were conducted simultaneously, so the observations collected after the first round of interviews were used to redevelop questions for the following rounds. The constant comparative method was used to analyze the data. The coding process included: open coding, axial coding, and selective coding phases.

Categorization of the interviews' led to identification of the emerging concepts and sub-concepts, that were integrated in the 4 main cognitive processes: collective sensing (perception), problem solving, decision making, and collective memorization (including learning and gaining feedback). The initial data collection protocol, redeveloped in the course of conducted interviews, was the basis for preparation of an evaluation framework presented in Table 2.

Table 2. Evaluation framework for the qualitative research of the cognitive processes enabling emergence of collective intelligence in policymaking projects

\section{Cognitive} Process
Interview questions for case evaluation 
- How the information is obtained from environment, how effective is this process and how it can be improved?

Collective - What is the level of cognitive diversity among the participants, is it adequate to the expectations; sensing does it help or is it interfering with the project?

- What kind of data (relevant information) have been identified, what is the degree of information "coverage" in relation to all the issues that are sensed, why were certain problems not identified?

- How do you rate the creativity of the participants and what supports it? Do unconventional and diverse ideas emerge?

- Are the ideas refined in the author-stakeholder interaction (with the participation of other residents of the district, experts, critics)? Are there any arguments for and against? How is the final proposal developed?

Problem - Is it possible to organize bottom-up social groups focused on ideas or important problems? What makes it easier?

- Do conflicts arise and how do they influence the debate?

- Do the stakeholders have their own specific group identity? How does it affect their involvement and why?

- How is the synthesis of a developed idea created? How is the redundancy reduced?

- How do the developed ideas help to create a "map" of local problems and needs (or model of the debated problem)? Is such a model created and has it got real-world applications?

- What is the process of pre-selecting solutions and their evaluation?

- How do prejudices and specific types of thinking influence decision making? Do prejudices and

Decision specific types of thinking help or hinder the making of commonly accepted decisions?

making

- What helps in setting priorities and in drawing conclusions from dispersed information? Is it possible to visualize the possible effects of projects?

- How is the voting and final selection process conducted?

- $\quad$ Are the results of the work recorded in the memory system available to all participants?

- Are the experiences of previous years recalled and used? To what extent? Is there any chance of not repeating the same mistakes?

Collective - Is feedback on the results of the implemented projects collected, and is it possible to actually memory learn from their experiences?

- Is there any evaluation of the results of the implemented projects and is it possible to draw conclusions from past mistakes and successes in the long term? What facilitates this process and what hinders it?

The complementary technique was based on the analysis of official reports on the evaluation of previous editions of Civic Budget and other local policy documents. The main documents used for this purpose were: the Evaluation Reports for 2020 CBCK Edition [90], for 2019 CBCK Edition [91], and for 2018 CBCK Edition [92], the initial presentation on CBCK statistics for 2020 prepared by city authorities [93], a local public opinion survey carried out at the request of the city authorities - "Barometr Krakowski" [94]. This combination of different data sources has achieved the triangulation of data, which was intended to ensure the reliability and validity of the findings, and reduce the level of inference errors [78].

\subsection{Overview of the Studied Case}

Participatory budgeting project Civic Budget of the City of Kraków, first implemented in 2013 as a pilot project allowing citizens to decide about local expenses in four districts of Kraków, and since 2014 implemented as a city-wide project. Each edition of the project is implemented in a cycle lasting 1 calendar year. The sixth edition, completed in 2020, was special for a number of reasons. Firstly, the participatory budget was record-high (over 7 million EUR), approx. 2.5 times higher than the budget for the year 2018. With respect to the allocated resources, it was the fourth highest participatory budget in Poland [91]. Secondly, both due to the external circumstances (the coronavirus pandemic) and the policy adopted by the local authorities, the whole project was implemented on 
Internet platforms. Online communication was not confined to voting - as it had been in previous years - but was also used during data collection, evaluation and deliberations about local needs. The public tasks proposed by the citizens of Kraków for implementation within CBCK can be carried out at two levels: district- and city-wide. Each budgeting project ends with a survey into the citizens' opinions. According to the survey, out of all of the aspects of CBCK's organization, the applicants rated highly the usefulness of the voting platform (86\% of positive opinions), ease of submitting task proposals (86\% of positive opinions), ease of voting (78\% of positive opinions) and communication with the task verifiers (78\% of positive opinions). The majority of negative opinions concerned the processing of filed protests (36\%), promotion of voting in CBCK (22\%) and the process of task proposal verification (14\%) [94]. The project activities are coordinated by the Civic Budget Council comprised of: representatives of urban activists, NGOs, informal groups, applicants, representatives of the Kraków City Council and representatives of district councils and administrations.

In many aspects, CBCK is a representative example of the way these types of projects are implemented in all large cities of Poland. The features which are indicative of its representative nature include: implementation under the auspices of local authorities with participation of district councils; information and promotion campaign encouraging citizens to participate; as well as regulation of the general participation rules and the status of the allocated part of the city budget by the government act of 11 November 2018 (Dz.U. 2018 item 130). Nearly 80\% of Kraków citizens declare that they are aware of CBCK, with $62 \%$ and $56 \%$ of people claiming that they know the rules and the manner of voting in CBCK respectively. Research shows that the essential information channels concerning CBCK are: Facebook (47\%), posters and leaflets (46\%) and a dedicated web portal, budzet.krakow.pl (43\%) [91]. At the same time, although CBCK belongs to the largest projects of this type in Poland when it comes to the budget, the voting participation is one of the lowest with just 5.96\% of residents voting in 2020 [93]. In comparison to the turnout in Zielona Góra (35\%), Olsztyn (31\%) and Łódź (24\%), this result is far below average. The reasons for this small attendance are reflected by the opinions expressed by the city's residents: according to a local survey carried out by Barometr Krakowski, only one in five inhabitants of Kraków feels like they have influence on local affairs (20\%), and nearly half of respondents claim having such influence is impossible, although they would like to have it (47\%). Only $16 \%$ of respondents indicated "voting in CBCK", and only $13 \%$ selected "submitting a project in CBCK", as the best way to gain influence on local affairs. It is worth mentioning that even though there has been a sharp increase in the budget over the last few years (from approx. 3 million EUR in 2018 to approx. 7 million EUR in 2020), this has not led to a real increase in interest and to a positive opinion about CBCK among the citizens [91, 92,93].

As a project, CBCK consists of several stages. The first stage is the so-called Educational Stage, whose aim is to encourage citizens to take part in consultations and to prepare their proposals for public actions. It includes discussions and debates, social dialogue, cooperation between applicants, and project-writing marathons. This stage is concluded by submitting "project sheets" - preliminary proposals for actions - by the citizens. Compared to the previous years, there was a significant change in 2020, which resulted both from the coronavirus pandemic and the general trend of digitalization, i.e. virtually all processes pertaining to debate, dialogue and cooperation between the citizens were implemented online. This sets the year 2020 apart from the previous years, where emphasis was placed on face-to-face meetings. At the same time, there has been a marked progress when it comes to online tools that make up CBCK's infrastructure. Preliminary actions involved the creation of Idea Bank BO 2020 (Bank Pomystów BO 2020), a collection of opinions about the citizens' most crucial needs, which were obtained electronically and presented visually in the form of a publicly available e-map (see: Fig. 1), that grouped ideas according to locations and categories (Security, Education, Road Infrastructure, Cycling Infrastructure, Culture, Sport and Sport Infrastructure, Society, Health, Greenery and Environmental Protection) [95]. The e-map of the citizens' needs, in 
conjunction with an electronic database of city-owned land (land on which public projects can be implemented) was supposed to constitute an introduction to a debate and an inspiration for project creators. Moreover, 34 inhabitants volunteered as debate coordinators (Local Participation Ambassadors) [96], whose task was to clarify any queries pertaining to the formalities, as well as to moderate the debate in a given field or social environment.

The information campaign in the year 2020 was mostly conducted on Facebook. When it comes to the total number of "followers" ("likes" and "follows"), the official CBCK page reached 20.1 thousand (as of 10/9/2020), which is the third highest result in Poland following Warsaw with 30 thousand followers and Wrocław with 23.5 thousand followers, and followed by Łódź with 12.7 thousand and Bydgoszcz with 10.1 thousand followers [90]. In order to support the debate, feedback, interaction and creation of new ideas, the city officially authorised the launch of 18 discussion groups called "Wspólne Projekty" (Joint Projects) on Facebook (1 group per each city district). Their purpose was to assist grassroots preparation of projects by local communities. These groups numbered 795 members in total, ranging from 12 to 134 per district (as of 1/5/2020 - last day of application submission), who were highly active - over 600 ideas and 1,000 comments were published across all groups [90]. Preliminary proposals for actions were commented on and the users created a network of cooperation, and tried to find common topics. Any inhabitant of a given district could join a group provided they accepted rules of communication ("discussion of the needs of a given district geared towards preparation of action proposals", "keeping to the topic and purpose of the group", "good manners and politeness", "no promotions or scam", "no hate and bullying") [97]. There were also many parallel groups created by grassroots on social media, where district inhabitants and local communities gathered to form new ideas (e.g. "Nowohucianie" with over 29 thousand members). The respondents of the evaluation survey conducted at the end of the 2020 edition of CBCK pointed to a significant role of Internet debates in shaping ideas, even though officially each idea was proposed by only one person: "Although I am the official applicant, all these projects were consulted with the residents. They were all their ideas, but since I was asked to submit them under my own name, this is what I did. [...] We communicate through Facebook. We have a housing estate group, where we informed the members that the deadline for submitting projects for the budget was drawing near, and we asked them to send in their ideas and needs" [90].

In the year 2020 the total of 988 proposals for actions were submitted to CBCK (a $4.5 \%$ increase compared to the previous year), most of which belonged to the following categories: Greenery and Environmental Protection (25\%), Infrastructure (23\%) and Sport \& Sport Infrastructure (16\%). Of all the submitted task proposals, 807 concerned districts, and 181 concerned the whole city [93]. It is striking, however, that the creative potential of the applicants from the previous editions of CBCK remains untapped. The vast majority $(84 \%)$ of applicants submit their task proposals only once, instead of trying to do the same in the following editions of CBCK [91]. Many of them are daunted by the process and results of the verification stage, and by limited communication with the city authorities. It would seem that the participants in previous editions should be natural partners in organising the process of drafting new task proposals and in engaging other citizens. Meanwhile, after one-time experience the majority decide to resign from taking part in the project. Currently, there are no activities aimed at creating lasting relations with these applicants, so the knowledge and experience they obtain are not taken advantage of in subsequent editions.

The remaining stages of the yearly project cycle include: verification of task proposals by experts to make sure that the proposals adhere to the CBCK Rules and Regulations; filing and processing of protests against experts' opinions; voting by citizens - indicating investment priorities; announcement of the tasks to be implemented, and their evaluation. The expert verification process constitutes a considerable obstacle: in the 2020 edition, $42 \%$ of task proposals were dismissed, mainly due to land ownership problems [93]. Additionally, it is not always possible to avoid project duplications. One of the ap- 
plicants described the following situation in the survey: "there were several identical projects, e.g. abreuvoirs or green bus/tram stops. Two projects called for "green bus stops", which resulted in votes for one initiative being spread across two projects, so even if the majority of people want green bus stops, the fact that the votes are spread across two nearly identical projects might mean that none of them gets a sufficient number of votes to win"[91].

The voting process was implemented mostly through an online platform (used by $73 \%$ of participants). The remaining votes were cast by ballot papers $(27 \%)$. Of the total of 44,800 votes cast in 2020, 42,281 were valid. As a result, 195 tasks were selected for implementation, of which 185 were district-wide and 10 were city-wide [90]. A vast majority of voters find the online voting platform useful and transparent (91\%) [91]. Opinions similar to the following ones are prevalent:"I think it was alright. I have no complaints. I think that a first time voter would know how to do it step by step. [...] What I liked about the voting platform was the ability to add the projects to a basket, so I can limit a long list of projects to only those that interest me, and focus on them"[90]. However, some people expressed various complaints about the platform. The most frequently mentioned problems concerned the search engine's performance and project filtering: "The search bar on the civic budget's website didn't work for me. I tried to search for a project by its name and it never came up, but when I typed the same name into Google, it did. [...] The feature I missed was an option to filter projects by specific fields. When we submit projects, we have to define a field, which becomes the project's symbol and we should be able to filter projects by that field in the app, because some people are interested in certain fields more than others, so this type of filter would be justifiable" [90].

The high turnover among people involved in the project was observed. So far over two thirds of CBCK voters participated in just one edition (68\%; 113 thousand people). Only 1,660 people have voted in all editions (1\%) [91]. This high percentage of one-time voters points to a lack of success in creating long-lasting relations, and to the fact that the experience and engagement obtained by the participants do not benefit subsequent editions of the project. Moreover, in the evaluation surveys, CBCK participants indicated that it would be helpful to have the ability to review archived projects on CBCK's website. The respondents are not aware that the website does contain this type of archive, although it is lacking in functionality [98]. This means that the archived knowledge about the previous experiences and implemented projects is not displayed sufficiently. A valuable but underutilized resource is suggestions that appear in evaluation surveys carried out at the end of each edition of the project, where respondents answer which new task proposals they expect to see next year. It is a repository of several thousand ideas which could serve as a base for a discussion about the needs of a given district, and as a source of inspiration for the creators of future activity proposals submitted within CBCK. Currently, such data is not processed in a way that would allow its visualization and utilization.

\subsection{Semi-Structured Interviews}

This section summarizes the highlights of all interviews. For a clearer understanding, the interview highlights are assigned to the categories of corresponding cognitive processes, identified during the coding phase. The first category that emerged as a result of coding the semi-structured interviews referred to the collective sensing process, i.e. social perceptiveness: ability to scan the environment, collect data on social needs, trends, possibilities, and good practices. As for the second identified category, problem solving, the most important factors influencing this process were recognized as creativity and self-organization. Creativity was observed primarily when new interactions were formed at the grassroots level. The category labeled as decision-making process covers both the pre-selection and initial evaluation of projects, as well as their final selection for implementation by the city's inhabitants through preferential voting. The last identified category was collective memory, i.e. aggregating experiences, learning, and gaining feed- 
back. Exclusions from the interviews assigned to such defined categories are presented in Table 3.

Table 3. Semi-Structured Interviews Summary

\section{Cognitive Process} Interview Highlights

- In the initial phase of the CBCK project an unexpectedly positive public response was observed. Newly created positions of Local Participation Ambassadors had a positive impact on the collection of data on local needs. "Collecting scattered opinions of the inhabitants using the Internet and translating them into proposals for action went surprisingly well [...]. The response was large and overwhelmingly positive".

- Most of the respondents claimed, that collecting data was continuous communication that raised the most important issues: "I assumed that 2-3 times a week I would post a report on my work and questions for residents on Facebook groups, and I gained feedback there. Thanks to the ongoing exchange of opinions, the residents asked directly for help in specific matters".

- When collecting opinions, the previously existing Internet communities of residents enjoyed greater popularity than the official CBCK discussion groups or the interactive Idea Bank. The amount of information that has been identified on the needs and expectations of residents has been assessed as fully sufficient to prepare adequate proposals for actions: "[...] The spectrum of topics is quite wide, so there is plenty to choose from".

- The large amount of generated data had not only a direct impact on the proposed initiatives, but also an indirect impact on city officials, who, having noticed an increased interest in a given topic, included it in urban programs and strategies. The impact on shaping the reality was twofold: both direct, through voting in $\mathrm{CBCK}$, and indirect, through shaping the policy of the city authorities: "Even projects that are not implemented or carried out on a micro scale, draw

\section{Collective sensing}

Problem solving attention to the fact that there are some topics important to the townspeople that the city should deal with. Officials can see that there is a problem, and it needs to be tackled on a larger scale".

- Most respondents believe that the identification of needs made it possible to capture the diverse expectations of the city residents, and none of the topics was over- or underrepresented. However, there were some opinions that cognitive diversity was not fully preserved because of the existence of strong activist circles (e.g., from schools, sport clubs, pro-ecological NGOs) that have been lobbying for certain solutions for years, and against which spontaneous grassroots initiatives are disadvantaged: "what is noticeable is the preponderance of pressure groups at the expense of the normies". Others drew attention to: "abuse, which I call the pathology of the city of retirees. Retirees have more time than other social groups, they firmly believe that their problems are the most important, and they want to impose this point of view on others". Sometimes, strong particular identities are also visible, e.g., groups of fans of competitive football clubs. On the other hand, in the opinion of some of the survey participants, the diversity is not fully preserved: people aged 35-50 are underrepresented because they are busy with their professional activity, which limits their time for social involvement. This is problematic, because this group is perceived as the city's most important taxpayers. However, collected opinions confirm, that these problems did not have a negative impact on the expected level of diversification of the topics discussed, and on the diversity of CBCK participants.

- The ethnic and cultural diversity of Krakow, which has been increasing in recent years as a result of immigration, helps to better identify the existing opportunities for action: "Thanks to the fact that we currently have residents who are Ukrainians, Belarusians, etc., our discussions contain examples and experiences from their previous places of residence".

- The focus on Internet communication forced by the coronavirus pandemic resulted in a significant increase in the creative activity of people who had not been associated with any official groups before (such as social clubs, NGOs, etc.). Creativity and self-organization in establishing "joint" projects was supported by Local Participation Ambassadors, who moderated the debate, as well as by the very nature of communication in social media, which enables simple and quick responses (e.g., short comments, "likes").

- The response to the submitted ideas, even if small, was a great motivation for their initiators, encouraging them to work on improving the projects. However, virtually every idea that ended in success required a strong leader who refined its content, verified its feasibility (especially the 
question of land ownership), as well as was able to make realistic cost assessments. The ideal model of cooperation was therefore an interaction between a strong leader who run the project and the local community who motivated the leader with their support.

- Presenting ideas via the Internet also prompted participants to actually consider arguments, instead of supporting the idea just because of neighborhood relations: "in the past, it was possible for people to run around the block and gather support from the neighbors. Now there are fewer neighborhood alliances, and we have more realistic projects".

- Despite the fact that there are more and more grassroots projects, this kind of projects still constitute a minority compared to the proposals of institutionally entrenched organizations or single individuals. It is estimated that approx. $35 \%$ of all of the prepared ideas were created as a result of deliberations within the official "Joint projects" Facebook groups and other online communities. However, according to some respondents, the strong identity of the circles that have been lobbying for specific solutions for years (e.g., the development of bicycle paths) might have an advantage over "joint" projects; these groups have an extensive experience in their narrow specializations, which results in the creation of more realistic solutions.

- The participants of the study paid special attention to the problems associated with the cooperation with the departments of the city hall responsible for verifying the legal aspects of the proposals, i.e., land ownership and other regulations affecting their feasibility. The online application provided by the city authorities, which allowed for a quick access to information on land ownership and the possibility of using it for investments, was found to be a positive factor supporting group cooperation. The respondents reported that the problem was not the lack of creativity of the city's inhabitants - this factor was rated highly - but rather the fears of city officials about the implementation of difficult and unconventional projects. Instead, they tend to discourage unusual projects so as to avoid extra work.

- Conflicts and disputes that arose in the course of the debates were seen by the survey participants as obstacles weakening the cohesion of the online communities and discouraging activity. Therefore, they believe that the ultimate goal of group work is supposed to be consensus. Nevertheless, our respondents do not think that conflicts dominated the debates. Rather, they see a greater obstacle to collective action in the excessive passivity of group members: "Up to the stage of formal evaluation of ideas conducted by the officials, cooperation and enthusiasm was high. Only in the course of interactions with the officials did disputes arise- most often over the location of the project. However, sometimes disputes help involve people in refining the idea because they make Ambassadors choose new locations together with the initiators, encourage more people to join the community around the idea, etc. (...) When there are signs of resistance from officials, social leaders often self-mobilize to keep their proposal from being scratched".

- Refining the ideas in interaction with the group, aggregating opinions and removing duplicates is often done in the course of negotiations. This is where municipal officials come in, whose task is to invite the authors of duplicated proposals to meetings (usually in the online form, e.g., using MS Teams): "We had two very similar projects submitted independently to establish a multicultural library. The applicants were invited to negotiate, they modified their assumptions a bit, they got along, and as a result, a single, even better project was created. It also drew the attention of officials responsible for libraries to the need for establishing such an institution, which is why foreign-language books have already started to be collected". However, "there are still situations where similar projects take each other's votes away, but the applicants do not wish to cooperate even after meetings". Sometimes this is due to the fact that the people who have been lobbying for certain solutions for years are afraid of losing their position if a similar idea is created independently. One of the participants provided an example: "I proposed a project involving the planting of 100 new trees in each district of the city. However, the environmentalists' association felt threatened by the fact that someone else was acting in "their" field, so they spoke out critically about my idea in the media. Still, my project was successfully implemented". 
- The survey participants gave a positive opinion about the voting procedure, saying that the existing online platform is transparent and easy to use. Certain reservations were raised about the fact that the voting resembles shopping in an online store (including "adding to basket" pre-selected solutions), but the vast majority of survey participants appreciate the simplicity and intuitiveness of the web application. The current system of preferential voting, allowing selection of three city-wide and three district projects, and prioritizing them from the most to the least supported, is also highly rated: "Preferential voting is a good solution. This prompts us to look at the various tasks and look at the problems of the city in a broader sense, not just at the one project that the participants intended to support. Second choice projects often win, which deepens reflection on what is generally worth doing in the city".

- The pre-selection phase and the preliminary feasibility evaluation of the project, managed by the Civic Budget Council, was reported as more controversial. This sub-process is intended to aggregate the generated opinions, remove duplicated and help to build syntheses. The accusation often made against the evaluators is that they were using discretionary evaluation criteria. The criteria for considering one initiative to be unfeasible and another to be feasible were found to be not entirely clear. One respondent described a case where two very similar projects, differing only in the title, were treated differently. Such behavior is seen as an example of superficial assessment. However, the respondents pointed out that the negative feasibility evaluation mainly concerned the proposals submitted by participants with little experience, most often participating in the CBCK project for the first time. By contrast, a number of cases were described where a proposal contested by the city officials for feasibility reasons was corrected and could be put to the vote.

Decision making

- Additional factors that potentially influenced decision-making included biases that affected voting, and the lack of extrapolation of the effects of the implemented projects. The participants of the study drew attention to the negative emotions that arose in their environment in relation to the ideological or political initiatives proposed in CBCK. Due to the increasing polarization in the country's political life, most city residents expect the local politics to be separated from ideological disputes. However, this kind of initiatives appeared very rarely, so they were not a major issue. A more frequent problem, however, was inability to extrapolate the long-term effects of the proposed projects, what was categorized as creation of structural model of the proposal. The respondents described situations in which the public were concerned about possible negative effects of particular investments. A noticeable group of city inhabitants were afraid of any changes in their surroundings because they believed that "[these projects] will generate a lot of yet unknown problems (...) Prejudices are growing around topics that generate excessive activity in the neighborhood".

- The participants of the study were generally convinced that building collective memory, aggregating experiences, learning, and gaining feedback, are all issues that cause the most trouble. The opinion that collective memory works only to a very limited extent was expressed by all of the respondents. They agree that a lot of work is done every year; primarily collecting opinions, discussions, negotiations, designing, presenting ideas and projects, but this whole thought process is preserved only fragmentarily, and there is very little chance of accessing and recovering knowledge.

- Communication is conducted using various platforms, but its results are not collected, or are very difficult to access. According to the respondents, this should be changed: "We should gather information on why some things succeeded, while others failed. The feedback we receive about the projects' development is weak, while it should be the most influencing factor in developing new ideas". Unfortunately, even people who are deeply involved in CBCK complain about the lack of feedback: "Many of the projects that were submitted failed for reasons that I do not know. Inhabitants often vote in favor of a promising project, but then these projects are not implemented for unknown reasons, or sometimes they come to fruition with a delay of several years". City residents often feel that the actions they contributed to by voting in CBCK resulted in unforeseen consequences that could have been avoided with a well-conducted evaluation taking into account past experiences and providing the possibility to recover and access them (categorized as meta-memory).

- The prevailing opinion is that at the system level, no one planned the creation of collective memory in CBCK and grouping experiences into blocks: "There are many people who do not have time to make their own proposals, but who could contribute their experiences to the debate. In turn, those who have achieved success should share their experiences. However, there is a lack 
of such activities in an organized form, there is insufficient space and not enough incentives for it".

- This problem is associated with the high turnover of people participating both in the preparation of projects and in voting in CBCK. People are discouraged because they do not notice the positive effects of the implemented activities, both on the Internet and in the urban space, even if such effects occur: "There is a lack of visual information in the city that some investments were made as a result of the civic budget. (...) There is also no information about the experiences so far, and about what worked. It's about showing the residents what has gone well and why. (...) The townspeople do not associate the investments they need with the civic budget, so they don't self-mobilize and do not fully believe that something can be changed".

- Local media also contribute to this, as according to the respondents they enjoy focusing on problems rather than presenting an objective picture of the situation: "The media are full of information about the failures of projects, but there is little information about achievements. This spreads a false, unrepresentative image. The negative aspects are disproportionately more publicized".

- $\quad$ Collective memory at the level of the city authorities and CBCK managers also does not work well: "The city authorities do not draw conclusions from the implemented projects. Officials rather discourage people from bold initiatives, make it difficult to collect data on relevant projects, do not support quality, but only simple solutions. Ideas that could capture the imagination and become the "flagship" achievements of the citizens' budget are rejected, such as the proposal to build a Formula 1 racetrack, which could not even be voted for. Another obstacle is the failure to draw conclusions from previous years regarding too low rates imposed by municipalities on project pricing, which in the past resulted in the limited viability of many projects".

- The participants of the study claimed that the CBCK council, which includes both representatives of the city hall and community organizations, is aware of the problem, but does not have a plan to find a remedy for the situation: "The budget council is constantly arguing about what went wrong. To understand this better, they use evaluation studies prepared by an external company, but the company writes the same thing every year, and most often it is not implemented. We are not able to check what actually worked, why something went well and what was worse, there is no visualization of what was done". According to the respondents, in subsequent editions of $\mathrm{CBCK}$, the same mistakes that have already occurred are often repeated.

\section{Results}

The conducted qualitative research has led to interesting results. First of all, it was possible to identify the operation of cognitive processes in the studied project. Categorization of the interviews' led to identification of the emerging concepts and sub-concepts, that were integrated in the 4 main cognitive processes: collective sensing, problem solving, decision making, and collective memorization. Thanks to the conducted data analysis it was possible to populate the initial theoretical basis with the collected experiences and concepts. The last stage of the planned study was integrating the concepts and connections that were proposed, to develop a narrative of the theory. It was followed by the extended literature review, aimed on farther populating the framework with references to the relevant literature on collective intelligence (CI), and the relevant literature on cognitive processes, to enhance the internal validity and theoretical quality of the framework. The results of this work were illustrated in the map of integrative findings, presenting the processes, sub-processes, and data related to collective intelligent decision-making.

The collective sensing process begins with gathering information through open-ended questions [99]; perceiving social data in the groups and communities [100], using selective approach to information globally assessed as relevant, as well as combining data from perception with top-down theories and models [36]. This process is a particular feature of the systems performing the "thin" cognitive processes: intelligence emerges from an assemblage of nonintelligent components, [...] by interconnecting in specific ways agents that are deliberately used as "sensors" of certain narrow segments of the world [...]. The "sensing" they accomplish can be complex and involve inner workings that are those of a fully intelligent creature [39]. One of the key concepts affecting this process is cognitive diversity, i.e. participation 
of people who have different ways of thinking, experiences, perspectives and cognitive abilities, and differences in demographic, educational and cultural backgrounds [73]. Nevertheless, this factor, as proved by Aggarwal et al., has a curvilinear - inverted (U-shaped) relationship with $\mathrm{CI}$, whence it follows that too much diversity can in some cases lead to a reduced CI level [101]. The amount of collected data is also important, because it translates into the possibility of extracting valuable information from the raw collection [102].

Problem solving process is related to an issue of creativity: a quality of actors in the system to generate new ideas [35]. Collective creativity, as $\mathrm{Yu}$ states, is about both the creativity of the output from a collective process and the creativity of the tasks performed as part of this process. Collective creativity involves several non-routine tasks out of which new ideas emerge [103]. The challenge is a design for the success of creative collaborations [104]. Next, refining the ideas and building an argument repertoire is conducted, as an indicator of enhanced epistemic grounding for opinion [56]. In an ideal situation deliberations are captured as topically-organized tree structures made up of questions to be answered, possible answers for these questions, and arguments [105]. The theoretical background of this approach is based on a scheme developed by H. Rittel and D. Noble, called the "Issue-Based Information System" [106]. Deliberation maps, as M. Klein states, have many advantages. If properly structured, every unique point appears just once, radically increasing the signal-to-noise ratio, and all posts must appear under the posts they logically refer to, so all content on a given question is co-located in the tree, making it easy to find what has and has not been said on any topic, fostering more systematic and complete coverage[...]. Careful critical thinking is encouraged, because users are implicitly encouraged to express the evidence and logic in favor of the options they prefer, and the community can rate each element of their arguments piece-by-piece [107]. One striking feature of collective problem solving is the question of group's self-organization. If the self-organization appears, it is manifested through flat relationships centered on achieving a common goal, not imposing formal structures, but leaving space for the non-formal leaders to appear [108]. The researchers also note that most of the CI systems will produce internal conflict [104]. In many cases criticality and conflict triggers the emergence of CI in groups [109]. This issue is directly related to the question of group identity [110], as well as to polarization [111] and/or balkanization, when participants self-organize into sub-groups wherein ideas rarely cross-fertilize across groups. This can be caused by social media tools (filter bubbles) or by people's tendency to find groups they can relate to (homophily) [105]. Finally, the complexity of cognitive operations related to the process of problem solving, was presented by Heylighen as building collective mental maps (CMM) [34]. Meaning the creation of a structural model for the debated problem, mapping its structure and interactions between participants, categorizing data and building an information hierarchy: various discoveries by members of the collective are being registered and stored in the CMM, so that the information will remain available for as long as necessary. CMM could have a form of registry of events or an edited collection of notes, it is a highly selective representation of features relevant to problem-solving [34].

The decision making process usually begins with an aggregation of the generated opinions and removing repetitions, that translates to building problem syntheses [36]. The epistemic quality of the system's products is directly dependent on the implemented aggregation mechanism [112]. The alternative solutions created in previous stages of work go through a process of systematic, well-reasoned evaluations, where all key arguments for and against an idea have been identified [105]. This kind of evaluation can be combined with "idea filtering", whose role is to eliminate, as much as possible, the incomplete or unsatisfactory ideas, so the community has the best possible alternatives at hand when it makes its final decisions [107]. Collective evaluation is effective in correcting individual biases in the overall task area of decision making [113]. Thanks to this process, the collective becomes aware of the biases' presence, and eliminates them, if they are harmful. Next, integration of the differentiated information takes place. The metric proposed for this aim by D. Engel is called "integrated information" or "phi". It was originally developed by neuroscientists as a measure of consciousness in brains' information to be integrated at the level 
of the system, as a whole integration of differentiated information is essential to the subjective experience of consciousness [102], and then adopted to the domain of CI. Finally, the natural culmination of the decision making process is a selection of one or more results to execute on. Inputs from participants are assembled to generate a decision that holds for the group as a whole. In some instances this decision determines [...] the subset of contributed items that will be included into the final output. In other instances [...] the decision relates to generating a common rank-ordering of the contributed items. In yet other instances, such as prediction markets, the decision relates to aggregating individual inputs to form a publicly visible estimate of a quantity. [35]. The most basic method for reaching collective decisions and avoiding conflicts is a simple majority vote: adding all the votes together determines the relative preferences of the different alternatives for actions [34]. Other common methods are: preference voting, where individuals can distribute their voting power over different alternatives, in proportion to their individual preference functions [34], weighted voting [114], or even utilizing decision made by experts [115].

The collective memory process is the final stage of the presented model. It also signals a return to the beginning of the cycle. The importance of this process is marked, because if it works well, it forms the basis for an increasing efficiency of "thinking" of a given community, gained in successive iterations of the activities described above. The most important elements of this process are: memorizing experiences, preferences, and conventions; accumulating the knowledge verified by practice; and developing a distributed memory system, to which all community members have access [108]. Just as individual intelligence is dependent on memory, the collective intelligence is dependent on collective memory [39]. When intelligence of a collective is extending not just through space (including many people), but also through time (including the knowledge of more than one generation), the room for both memory and experience is made [116]. The results of collective work, if they are confirmed by lived experience accumulated through repeated testing in practice, are stored in collective memory as points of reference [112]. The literature provides plenty of examples of swarm intelligence systems that display the characteristics of a shared memory: the behavior of social insects, e.g. foraging of ants, the nest-site selection and the nest building of termites, are probably the most classic examples [108].

In the memorization process the collected experiences and other results of problem solving and decision-making are grouped, archived in blocks, and stored in a shared data resource, so that the information will remain available for as long as necessary for the community members and for other interested parties [34]. When considering this process, both the use of short-term and long-term memory are analyzed [117]. Short-term memory is valid for the improvement and acceleration of current reasoning skills, while long-term memory allows, by gathering experiences, the accumulation of knowledge about the long-lasting effects of the activities carried out ("collective wisdom") [116]. Giving access to the accumulated knowledge also requires the creation of a meta-memory, or the set of processes for accessing and recovering knowledge, as well as organizing the information [112]. The result is the possibility of practical application of the accumulated knowledge to improve the work of the entire cognitive system through constant learning, and by gaining feedback, and making predictions. The feedback mechanism interacts with collective memory in a non-linear way: a trail leading to a good source will be reinforced through a positive feedback loop, while a trail leading to an empty source will spontaneously decay [34]. A memory-prediction framework, as described by Hawkins, presents the whole process of thinking as based on remembering sequences of events and their nested relationships, and making predictions based on those memories, which is much more efficient than a logical analysis of each encountered problem or challenge [118].

The proposed map of integrated findings, based on the data presented above, is shown in Figure 1: 


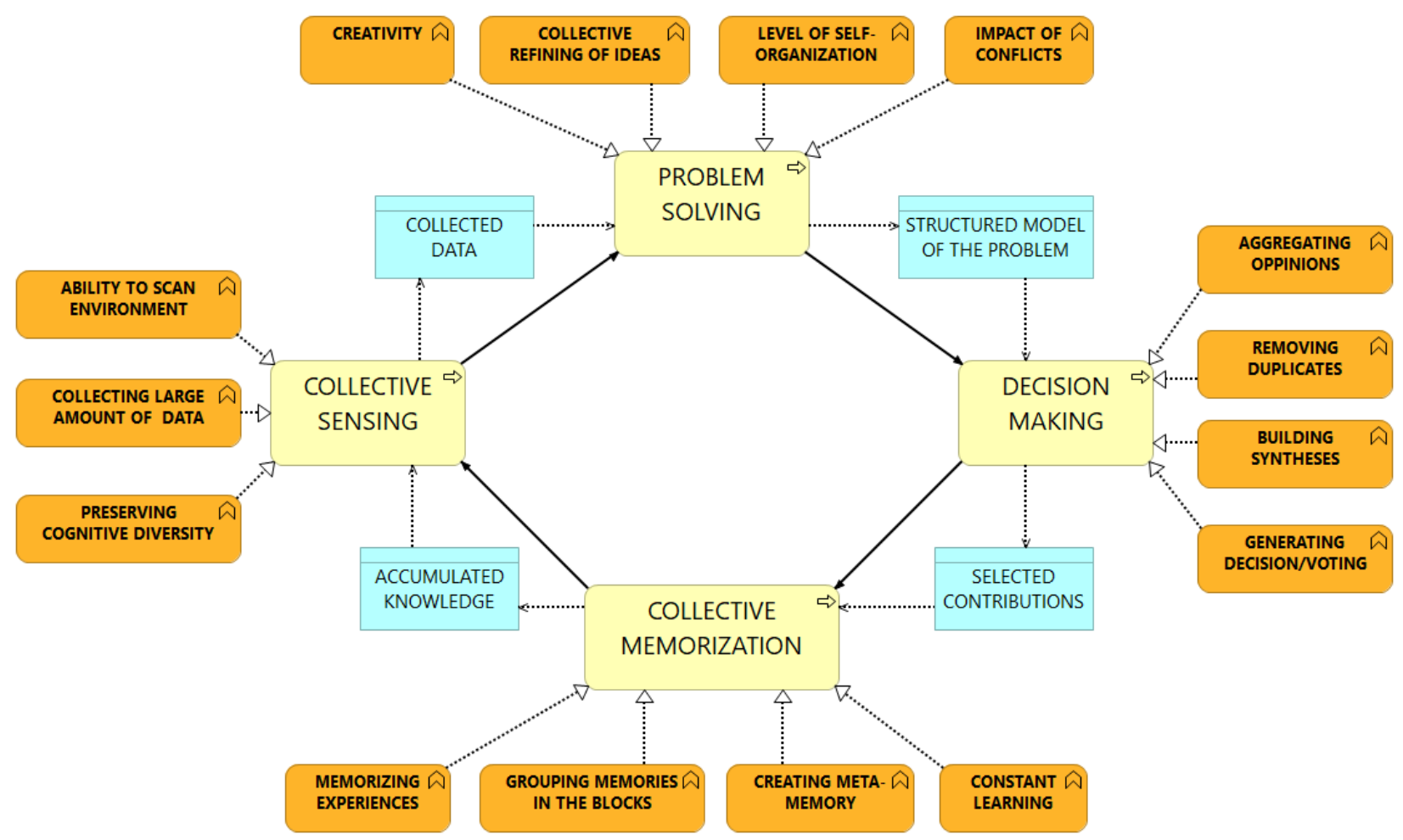

Fig. 1. Cognitive processes, sub-processes and data influencing the emergence of collective intelligence in policymaking.

According to the grounded theory methodology, in order to prove the validity of the presented theory, it should be confirmed by subsequent case studies. These studies may be carried out in the future on the basis of the data collection protocol presented in Section 3. All interested researchers are encouraged to pursue this topic further.

\section{Discussion and Conclusions}

With this case study was made an attempt to identify and assess, in a singular e-participation project, the cognitive processes which enable the emergence of collective intelligence $(\mathrm{CI})$ affecting group decision-making. The empirical work suggests that the emergence of $\mathrm{CI}$ in the analyzed project depends on the cognitive processes described above. The developed theory revealed the relations existing between categorized cognitive processes. The decision-making process, as an element of the analyzed group intelligence system, is presented by the interviewees as strictly connected and dependent on the other categorized cognitive processes.

However, interesting conclusions appear when we compare the differences in the qualitative assessment of individual cognitive processes carried out by the survey respondents. Data analysis proved that most of the processes are working relatively well, with one notable exception: the process of collective memory works only to a very limited extent. Basically, all respondents claimed that memory-related operations are the most important problem. The studied project seems to repeat similar errors in successive iterations, new participants seldom use past experiences, and after participating in the processes once they do not remain a part of the system. Also, learning mechanisms do not work well in practice. A cognitive system operating in this way has difficulty delivering intelligent results because, as cognitive psychology proves, all system operation depends on memory and continuous learning, which forms the basis for an increasing efficiency of "thinking" of a given community.

According to the survey participants, information about the experiences and achievements developed so far, even if available somewhere on the Internet, is very difficult to find and not linked together in a logical structure. The results of the study show that the observations and conclusions that emerge from debates conducted on dispersed 
Facebook groups and in the other social media are irretrievably lost. Furthermore, the advanced communicative actions(as defined by Habermas [119]), such as the negotiations held by municipal officials, during which the opinions are aggregated and duplicating projects are merged, could be an extraordinary source of collected practical wisdom, proven by experience. However, this potential is not used. The answers of the respondents indicate that, in the current model, knowledge gathering takes place only when "experienced" NGOs and social groups develop their organizational memory separately, in their field of narrow specialization, acting independently of each other and, as it were, outside the system. In such a situation, it is difficult to build an integrated system that allows for the shared use of memory resources. The accumulated knowledge has the potential to improve the work of entire cognitive system through constant learning, by gaining feedback, and by making predictions, becoming the basis for an increasing efficiency of intelligence across the whole community. Instead, the project repeats similar errors in successive iterations, new participants rarely use past experience, and after participating in the processes once, they do not remain part of the system.

The problems related to the collective memory process are confirmed not only by the semi-structured interviews, but also by the second method that was adopted, i.e.examining documents obtained through desk research. The high turnover among people involved in the project means that that the creative potential of the applicants from the previous editions of $C B C K$ remains untapped. A large number of participants get discouraged upon encountering problems, which, instead of being a valuable lesson learnt in the following years, is repeated by subsequent groups of people. Of course, the situation in which certain groups of participants are replaced by others is normal, but the desired course of action would be to use the organization's memory rather than starting all over again. Therefore, creating lasting relations with the participants especially to keep them in the project, is one of the most important tasks of the CBCK managers.

The identified problem is especially important, as memory-related cognitive processes are considered crucial for the functioning of the entire intelligence system, both in relation to the individual's intelligence and collective intelligence. For, as J. Hawkins notices, memory allows every thinking being to effectively manage the energy of the entire system. Thanks to memory, we do not waste energy analyzing the same activities over and over again. Attention and focus are "rare", valuable resources, so thanks to the use of behavioural patterns stored in memory gained through feedback and learning, we do not distract attention from unnecessary details [118]. The same, as Mulgan notes, applies for collective intelligence: memory and learning are the most important cognitive factors, thanks to which we can accumulate the knowledge verified by practice, and, consequently, we are rethinking how we think [37].

Revealing that most cognitive processes in online e-participation projects and their system environments are working satisfactorily, but that their real weakness is using collective memory, can significantly improve the quality of such projects in the future. This work could further be enriched with a guide for policymakers including the development of a shared memory system, to which all community members have access, enabling them to save and structure information, access and recover knowledge, as well as make predictions based on the gathered data.

The presented study is not free of limitations. The survey was conducted with a limited group of respondents, and its subject was a single project. The sample used may be considered relatively small, however it is a contribution to further work that will allow one to confirm the observed phenomenon in a wider dimension in the future. Further studies, also using quantitative methods, need to be planned to confirm the observed phenomena.

Funding: This research was funded by Narodowe Centrum Nauki (National Science Centre, Republic of Poland), the research grant UMO-2018/28/C/HS5/00543 - "Collective intelligence on the Internet: applications in the public sphere, research methods and civic participation models" 
(“Kolektywnainteligencja w Internecie: zastosowania w sferzepublicznej, metodybadaniaimodelepartycypacjiobywatelskiej").

Conflicts of Interest: The author declare no conflict of interest. The funders had no role in the design of the study; in the collection, analyses, or interpretation of data; in the writing of the manuscript, or in the decision to publish the results.

\section{Appendix A}

The following is a brief description of the work performed prior to the study described in the main research article. This first part of work was focused on the review of the methods and strategies so far proposed for the study of online collective intelligence (CI) in public policy. The method used for this purpose was a meta-systematic literature review, following RAMESES standards [57]. The main reason for choosing this method was the heterogeneity of the topic. Contemporary studies on CI, although clearly inspired by the development of the Internet in its origins, have so far been carried out in very diverse disciplines, from biology, through social sciences and organization management, to artificial intelligence. For this reason, it was necessary to narrow this literature review to works related to the use of $\mathrm{CI}$ in online activity. Additionally, when selecting keywords, alternative terms of CI used in the literature were taken into account, including:"crowdsourcing" [120], "swarm intelligence" [121], "wisdom of crowds" [72], "crowdlaw" [122]. These concepts, although not fully identical, have an established position, and are used by researchers to describe similar phenomena, depending on the background of individual authors (the relationships and differences between these concepts were described by Buecheler[123]). The second set of keywords included concepts related to political science, administration, and governance:"policymaking" (variants: "policy-making" and "policy making"), "public policy", "political science", "public administration", "public sector", "public governance". The Web of Science was chosen from a number of pre-selected databases (other databases considered were: Scopus, ScienceDirect and EBSCO) because of its reputation for the greatest coverage and the greatest impact in terms of most cited authors and articles [124] as well as for the most accurate subject classification [125]. Search engines, such as Google Scholar, were excluded, as the priority was to select peer-reviewed publications. The timeframe for the search was set for the period from 2010 to 2019. The data search was conducted on October 8,2020 . The logical search was applied to the topic (including abstract, keywords, and indexed fields), as well as the titles of the scientific articles. The inclusion criteria have been focused on peer-reviewed scientific articles dealing with issues in the field of public policymaking and combining them with methods, models and concepts derived from the CI domain.

The logical search used the following syntax: TS=(("Collective Intelligence" OR "Crowdsourcing" OR "Swarm Intelligence" OR "Wisdom of crowds" OR "Crowdlaw") AND ("Policy Making" OR "Policy-making" OR "policymaking" OR "Public Policy" OR "Public Administration" OR "Political Science" OR "Public Sector" OR "Public Governance" OR "e-participation")) OR TI = (("Collective Intelligence" OR "Crowdsourcing" OR "Swarm Intelligence" OR "Wisdom of crowds" OR "Crowdlaw") AND ("Policy Making" OR "Policy-making" OR "policymaking" OR "Public Policy" OR "Public Administration" OR "Political Science" OR "Public Sector" OR "Public Governance" OR "e-participation")).

This search led to an initial number of 170 references. Then, in accordance with the guidelines of $\mathrm{H}$. Snyder, the content of all articles was reviewed in terms of checking the inclusion criteria, according to the title-abstract-references scheme [58], which allowed to identify the content that did not meet the criteria described above and remove it from the database. The next step was identification of the core contributions, along with the RAMESES standards, and verification of the scholarly literature listed in these core contributions to extend the database including the "seminal", or revealing sources, as well as monographs. To focus on high-quality literature, an exclusion of the conference pro- 
ceedings and the reviews have been made. Also, the irrelevant WoS cathegories were excluded, primarily: Business (due to the exclusion of commercial projects from the analysis), Medical Ethics, Surgery. In addition, studies that did not concern online projects were omitted. This led to the refined list of 75 results.

At that point, a narrative review and meta-analysis of the content of the articles were performed. As a result, 15 methods and strategies for studying CI in public policymaking projects were identified. Each of the analysed texts was assigned a min. of 1 and a max. of 4 methods and strategies, presented in the main text of this article in Table 1.The performed review proved, that no method of studying CI in the online policymaking projects, based on the analysis of group cognition processes, has been described so far in the literature indexed in Web of Science database.

The second part of the literature review was aimed on creating theoretical basis for the outline of evaluation framework of collective cognition. Therefore, the sets of keywords included: "group cognition" or "collective cognition" or "group cognitive process" or "collective cognitive process" and "framework" or "theoretical framework". The Web of Science was chosen again as the platform of search. The timeframe for the search was set for the period from 2010 to 2019. The data search was conducted on October 19, 2020. The logical search was applied to the topic (including abstract, keywords, and indexed fields), as well as the titles of the scientific articles. The logical search used the following syntax: TS=(("Group cognition" OR "Collective cognition" OR "Group cognitive process" OR "Collective cognitive process") AND ("Framework" OR "Theoretical framework")) OR $\mathrm{TI}=(($ "Group cognition" OR "Collective cognition" OR "Group cognitive process" OR "Collective cognitive process") AND ("Framework" OR "Theoretical framework")). To focus on high-quality literature, an exclusion of the conference proceedings and the reviews has been made.

As a result, the refined list of 15 scientific articles were obtained. The qualitative analysis of these results proved again, that no framework for evaluation of group cognitive processes in policymaking existed before in the reviewed literature. After a qualitative analysis of the results obtained, it was decided to choose as the theoretical basis to be farther developed the Multiple, Interacting Levels of Cognitive Systems (MILCS) perspective, as proposed by R. Goldstone and G. Theiner.

\section{References}

1. Milano, M.; O'Sullivan, B.; Gavanelli, M. Sustainable Policy Making: A Strategic Challenge for Artificial Intelligence. AI Mag2014, 35, 22-35.

2. Valle-Cruz, D.; Criado, J.I.; Sandoval-Almazán, R.; Ruvalcaba-Gomez, E.A. Assessing the public policy-cycle framework in the age of artificial intelligence: From agenda-setting to policy evaluation. Government Information Quarterly2020, Volume 37, Issue 4, doi.org/10.1016/j.giq.2020.101509.

3. Gavanelli, M.; Riguzzi, F.; Milano, M.; Cagnoli, P. Constraint and Optimization Techniques for Supporting Policy Making. In Computational Intelligent Data Analysis for Sustainable Development, Yu, T., Chawla, N., Simoff, S. Eds., Chapman \& Hall/CRC: London, UK, 2013.

4. Greenemeier, L. Smart Machines Join Humans in Tracking Africa Ebola Outbreak. Available online: https://www.scientificamerican.com/article/smart-machines-join-humans-in-tracking-africa-ebola-outbreak/ (accessed on 2020-09-22).

5. McKelvey, F.; MacDonald, M. Artificial intelligence policy innovations at the Canadian Federal Government. Canadian Journal of Communication 2019, 44(2), 43-50.

6. Joyner-Roberson, E. What do drones, AI and proactive policing have in common? Available online: https://www.sas.com/en za/insights/articles/risk-fraud/drones-ai-proactive-policing.html (accessed on 2020-09-22).

7. Sun, T. Q.; Medaglia, R. Mapping the challenges of artificial intelligence in the public sector: Evidence from public healthcare. Government Information Quarterly2019, 36(2), 368-383.

8. Grothaus, M. China's airport facial recognition kiosks should make us fear for our privacy. Available online:https://www.fastcompany.com/90324512/chinas-airport-facial-recognition-kiosks-should-make-us-fear-for-ourprivacy (accessed on 2020-09-22). 
9. Vicente, M.R.; Novo, A., An empirical analysis of e-participation. The role of social networks and e-government over citizens' online engagement. Government Information Quarterly 2014, 31, 379-387.

10. Saebø, Ø., Rose, J.; Flak, L. S. The shape of eParticipation: Characterizing an emerging research area. Government Information Quarterly2008, 25, 400-428.

11. Dixon, B. E. Towards e-Government 2.0: An assessment of where e-Government 2.0 is and where it is headed. Public Administration $\mathcal{E}$ Management2010, 15 ( 2 ): 418 - 454.

12. Osimo, D. Web 2.0 in Government: Why and How? Office for Official Publications of the European Communities: Luxembourg, 2008.

13. Kim, S.; Lee, J., E-Participation, Transparency, and Trust in Local Government. Public Administration Review2012, Volume 72, Issue $6,819-828$.

14. Madero, V.; Morris N. Public participation mechanisms and sustainable policy-making: a case study analysis of Mexico City's Plan Verde, Journal of Environmental Planning and Management2016, 59:10, 1728-1750, doi:10.1080/09640568.2015.1085841.

15. Gil, O.; Cortés-Cediel, M.E.,; Cantador, I. Citizen participation and The Rise of Digital Media Platforms in Smart Governance and Smart Cities. International Journal of E-Planning Research2019, 8 (1), 19-34.

16. Cantador, I.; Bellogín, A.; Cortés-Cediel, M. E.; Gil, O. Personalized recommendations in eparticipation: Offline experiments for the 'Decide Madrid' platform. In: Proceedings of the 1st International Workshop on Recommender Systems for Citizens, 2017.

17. Konopacki, M., Albu, D., Steibel, F. MUDAMOS: a civil society initiative on collaborative lawmaking in Brazil, Proceedings of the $12^{\text {th }}$ International Conference on Theory and Practice of Electronic Governance (ICEGOV2019), Edited by: BenDhaou, S; Carter, L; Gregory, M., Pages: 175-180, doi: 10.1145/3326365.3326388.

18. Landemore, H. When public participation matters: The 2010-2013 Icelandic constitutional process. International Journal of Constitutional Law2020, Vol 18 Issue: 1, pp: 179-205, doi: 10.1093/icon/moaa004.

19. Tseng, Y. A comparative analysis of Decide Madrid and vTaiwan, two Digital Platforms for Political Participation, Durham theses, Durham University. Available online: http://etheses.dur.ac.uk/13703/, (accessed on 2020-10-08).

20. Royo, S.; Pina, V.; Garcia-Rayado, J. Decide Madrid: A Critical Analysis of an Award-Winning e-Participation Initiative. Sustainability2020, 12, 1674.

21. Lackaff, D. Better Reykjavik - Open Municipal Policymaking. In: Civic Media: Technology, Design, Practice. Gordon, E; Mihailidis, P., Eds.; MIT Press: Cambridge, MA, United States, 2016.

22. Rahvakogu. Available online: https://rahvakogu.ee/ (accessed on 2020-10-10).

23. Submit evidence to a committee inquiry. Available online: https://www.parliament.uk/get-involved/committees/, (accessed on 2020-10-10).

24. Toots, M. Why E-participation systems fail: The case of Estonia's Osale.ee. Government Information Quarterly2019, https://doi.org/10.1016/j.giq.2019.02.002.

25. Bonsón, E.; Torres, L.; Royo, S.; Flores, F. Local e-government 2.0: Social media and corporate transparency in municipalities. Government Information Quarterly 2013, 29, 123-132.

26. Brainard, L.A.; McNutt, J.G. Virtual Government-Citizen Relations: Informational, Transactional, or Collaborative? Adm. Soc.2010, 42, 836-858.

27. Criado, J.I.; Rojas-Martín, F. Adopting Social Media in the Local Level of Government: Towards a Public Administration 2.0? In Social Media and Local Governments: Theory and Practice; Sobaci, M.Z., Ed.; Springer International Publishing: Cham, Switzerland, 2016; pp. 135-152.

28. Bertot, J. C.; Jaeger, P. T.; Hansen, D. (2012). The impact of polices on government social media usage: Issues, challenges, and recommendations. Government Information Quarterly2012, 29, 30-40. http://dx.doi.org/10.1016/j.giq.2011.04.004.

29. Picazo-Vela, S.; Gutierrez-Martinez, I.; Luna-Reyes, L. F. Understanding risks, benefits, and strategic alternatives of social media applications in the public sector. Government Information Quarterly2012, $29(4)$, 504-511. http://dx.doi.org/10.1016/j.giq.2012.07.002.

30. Panopoulou, E.; Tambouris, E.; Tarabanis, K. Success factors in designing eParticipation initiatives. Information and Organization 2014, 24, 195-213.

31. Font, J.; Navarro, C. Personal experience and the evaluation of participatory instruments in Spanish cities. Public Administration 2013, 91, 616-631.

32. Levy, P. L'intelligence collective: Pour uneanthropologie du cyberspace. Editions La Decouverte. English edition: Collective Intelligence: Mankind's Emerging World in Cyberspace, Plenum, 1997.

33. Pór, G. Questing for Collective Intelligence. In: Community Building in Organizations: Renewing Spirit and Learning in Business. ed.; Gozdz, K., New Leaders Press: San Francisco, CA, United States,1995. 
34. Heylighen, F. Collective Intelligence and its Implementation on the Web: Algorithms to Develop a Collective Mental Map. Computational \& Mathematical Organization Theory 1999, 5:3, 253-280.

35. Malone, T. W.; Laubacher, R.; Dellarocas, C. The Collective Intelligence Genome. MIT Sloan Management Review2010, Vol. 51(3), pp. 21-31.

36. Goldstone, R.L.; Theiner, G. The Multiple, Interacting Levels of Cognitive Systems (MILCS) Perspective on Group Cognition. Philosophical Psychology 2017, Vol. 30, Issue: 3, pp. 334-368. DOI: 10.1080/09515089.2017.1295635.

37. Mulgan, G. Big Mind. How Collective Intelligence Can Change Our World. Princeton University Press, Princeton, NJ, United States, 2018.

38. Steyvers, M.; Miller, B. Cognition and Collective Intelligence, In Handbook of Collective Intelligence, Malone, T., Bernstein, M.S., Eds.; The MIT Press: Cambridge, MA, United States, 2015.

39. Andler, D. What Has Collective Wisdom to Do with Wisdom? In Collective Wisdom, Landemore, H., Elster, J., Eds.; Cambridge University Press: New York, NY, United States, 2012.

40. Fadul, J.A. Collective Learning: Applying Distributed Cognition for Collective Intelligence. The International Journal of Learning 2009, Volume 16, Number 4.

41. Charmaz, K. Constructing grounded theory: A practical guide through qualitative analysis. Sage: Thousand Oaks, CA, United States, 2006.

42. Ostrom, E. Governing the Commons: The Evolution of Institutions for Collective Action. Cambridge University Press: Cambridge, $\mathrm{UK}, 1990$.

43. Long, M. Beyond traditional boundaries: Government in the information age. Australian Journal of Public Administration2002, 61(1), 3-12.

44. Owen, J.; Connor, J.; Linger, H. Project management as a tool of policy implementation. Paper presented at PMI ${ }^{\circ}$ Research and Education Conference, Limerick, Munster, Ireland. Newtown Square, 2012, PA: Project Management Institute.

45. Transforming our world: the 2030 Agenda for Sustainable Development. Available online: https://sdgs.un.org/2030agenda (accessed on 2020-09-18).

46. Piotrowski, S.; Van Ryzin, G. Citizen Attitudes Toward Transparency in Local Government. The American Review of Public Administration 2007, 37(3) 306-323.

47. Chun, S.A.; Shulman, S.; Sandoval, R.; Hovy, E. Government 2.0: Making Connections Between Citizens, Data and Government. Information Polity2010, 15(1).

48. Habermas, J. The Structural Transformation of the Public Sphere. Polity: Cambridge, UK, 1989.

49. Wolfe, J. Varieties of Participatory Democracy and Democratic Theory. Political Science Reviewer1986, 16 : 1-38.

50. Pateman, C. Participatory Democracy Revisited. Perspectives on Politics2012, 10 (1): 7-19. doi:10.1017/S1537592711004877

51. Sintomer, Y; Herzberg, C., Rocke, A. Participatory budgeting in Europe: Potentials and challenges. International Journal of Urban and Regional Research 2008, 32(1):164-178.

52. Osborne, S. The New Public Governance?.Public Management Review2006, 8:3.

53. Osborne, S. ed. The New Public Governance? Emerging Perspectives on the Theory and Practice of Public Governance. Oxford University Press: Oxford, UK, 2009.

54. Ansell, C.; Gash A. Collaborative Governance in Theory and Practice. Journal of Public Administration Research and Theory 2007, $18: 4$.

55. Emerson, T.; Nabatchi, T.; Balogh. S. An Integrative Framework for Collaborative Governance. Journal of Public Administration, Research andTheory2021, 22:1.

56. Capella J.N.; Zweng, J.; Price, V. Collective Intelligence: The Wisdom and Foolishness of Deliberating Groups. In The Oxford Handbook of Political Communication, 1 1 ${ }^{\text {st }}$ ed.; Kenski, K., Jamieson, K.H. Eds.; Oxford University Press: Oxford, UK, 2017.

57. Wong, G., Greenhalgh, T., Westhorp, G., Buckingham, J., Pawson, R. RAMESESpublication standards: Meta-narrative reviews. BMC Medicine2013, 11, 20. https://doi.org/10.1186/1741-7015-11-20.

58. Snyder, H. Literature review as a research methodology: An overview and guidelines. Journal of Business Research, 2019, Vol. 104, pp. 333-339.

59. Torraco, R. J. Writing Integrative Literature Reviews: Guidelines and examples. Human Resource Development Review 2005, Vol. 4, pp. 356-367. https://doi.org/10.1177/1534484305278283.

60. Sternberg, R.J., Sternberg, K. Cognitive Psychology. 6th ed.;. Wadsworth, Cengage Learning: Belmont CA, United States, 2012.

61. Neisser, U. Cognitive psychology. Prentice-Hall, Inc.: Englewood Cliffs, NJ, United States, 1967.

62. Cattell, R. B. Theory of fluid and crystallized intelligence: A critical experiment. Journal of Educational Psychology1963. 54: 1-22. doi:10.1037/h0046743.

63. Horn, J. L. Intelligence: Why it grows. why it declines. Trans-action1969, 4, 23-31. 
64. Landemore, H. Democratic Reason: Politics, Collective Intelligence, and the Rule of the Many. Princeton University Press: Princeton, NJ, United States, 2012.

65. Huebner, B. Macrocognition. Oxford University Press: New York, NY, United States, 2013.

66. Stahl, G. Group cognition: Computer support for building collaborative knowledge. MIT Press: Cambridge, MA, United States, 2006.

67. Stahl, G. Studying virtual math teams. Springer Verlag: New York, NY, United States, 2009.

68. Theiner, G.; Goldstone, R. L. Recognizing group cognition. Cognitive Systems Research 2010, 11, 378-395.

69. Woolley, A. W.; Chabris, C. F.; Pentland, A.; Hashmi, N.; Malone, T.W. Evidence for a Collective Intelligence Factor in the Performance of Human Groups. Science2010, Vol. 330(6004): 686-688.

70. Heylighen, F.; Heath, M.; Van Overwalle, F. The emergence of distributed cognition: A conceptual framework. Proceedings of Collective Intentionality IV, Siena, Italy, 2004.

71. Malone, T. W. Superminds. Little, Brown: New York-Boston-London, United States, UK, 2018.

72. Surowiecki, J. The Wisdom of Crowds. Anchor Books: New York, NY, United States, 2005.

73. Hong, L.; Page, S. Groups of Diverse Problem-solvers Can Outperform Groups of High-ability Problem-solvers. PNAS2004, Vol. 101, pp. 16385-16389.

74. Corbin, J.; Strauss, A. Basics of qualitative research (3rd ed.). Sage: Thousand Oaks, CA, United States, 2008.

75. Crossan, M. M.; Berdrow, I. Organizational learning and strategic renewal. Strategic Management Journal2003, 24(11), 10871105.

76. Pandey, S. C.; Dutta, A. Role of knowledge infrastructure capabilities in knowledge management. Journal of Knowledge Management2013, 17(3), 435-453.

77. Sivarajah, U., et al., Evaluating the use and impact of Web 2.0 technologies in local government. Government Information Quarterly2015, http://dx.doi.org/10.1016/j.giq.2015.06.004.

78. Yin, R. K. Case study research: Design and methods, 4th Ed. Sage: Thousand Oaks, CA, United States, 2009.

79. Dyer, W.G.; Wilkins, A.L. Better stories, not better constructs, to generate better theory: A rejoinder to Eisenhardt. The Academy of Management Review 1991, 16(3), 613-619.

80. Eisenhardt, K.M. Building theories from case study research. The Academy of Management Review1989, 14(4), 532-550.

81. Gable, G.G. Integrating case study and survey research methods: An example in information systems. European Journal of Information Systems1994, 3(2), 112-126

82. de Sousa Santos, B. Participatory Budgeting in Porto Alegre: Toward a Redistributive Democracy. Politics E Society1998, 26(4):461-510. doi:10.1177/0032329298026004003.

83. Bingham, L.B.; Nabatchi, T.; O'Leary, R. The new governance: practices and processes for stakeholder and citizen participation in the work of government. Public Adm Rev2005;65(5):547-58.

84. Bland, G. Supporting Post-conflict Democratic Development? External Promotion of Participatory Budgeting in El Salvador. World Development 2011, Volume: 39, Issue: 5, pages: 863-873.

85. Wampler, B. A guide to Participatory Budgeting. In Participatory Budgeting, A. Shah, Ed.; pp. 21-54. The World Bank, 2007. https://doi.org/10.1596/978-0-8213-6923-4.

86. Džinić, J.; Murray Svidroňová, M.; Markowska-Bzducha, E. Participatory Budgeting: A Comparative Study of Croatia, Poland and Slovakia. NISPAcee Journal of Public Administration and Policy2016, Volume 9: Issue 1, https://doi.org/10.1515/nispa-2016-0002.

87. Madej, M. Participatory Budgeting in the Major Cities in Poland - Case Study of 2018 Editions. Politics in Central Europe2019, 15(2):257-277, DOI: 10.2478/pce-2019-0017.

88. Given, L. The SAGE Encyclopedia of Qualitative Research Methods; Sage Publications: London, UK, 2008.

89. Reis, J.; Santo, P.; Melão, N. Impact of Artificial Intelligence Research on Politics of the European Union Member States: The Case Study of Portugal. Sustainability2020, 12, 6708; doi:10.3390/su12176708.

90. Raport z ewaluacjiprocesuwdrażania VII edycjibudżetuobywatelskiegomiastaKrakowa 2020. Available online: https://budzet.krakow.pl/zalacznik/375080 (accessed on: 2021-01-18).

91. RaportEwaluacyjny. VI edycjaBudżetuObywatelskiegoMiastaKrakowa 2019. Available online: https://www.bip.krakow.pl/plik.php?zid=259425\&wer=0\&new=t\&mode=shw (accessed on: 2021-01-18).

92. RaportEwaluacyjny. V edycjaBudżetuObywatelskiegoMiastaKrakowa $2018 . \quad$ Available online: https://budzet.krakow.pl/zalacznik/331234 (accessed on: 2021-01-18).

93. BudżetObywatelskiMiastaKrakowa. Available online: https://budzet.krakow.pl/zalacznik/372206 (accessed on: 2021-01-18).

94. BarometrKrakowski. RaportBadawczy. Badaniesocjologiczneprzeprowadzone w Krakowiemaj - lipiec 2018. Available online: http://barometrkrakowski.pl/wp-content/uploads/2019/02/Barometr-Krakowski-2018.-Raport-badawczy.pdf (accessed on: 2021-01-18). 
95. Bank Pomysłów BO 2020. Available online:

https://msip.um.krakow.pl/portal/apps/webappviewer/index.html?id=b7e270d2728f44908374ccd910c2210b\&_ga=2.195491244. 1074674978.1603914287-495396393.1599654018 (accessed on: 2021-01-18).

96. AmbasadorzyLokalnejPartycypacji 2020. Available online: https://budzet.krakow.pl/strona glowna/237750,artykul,lista ambasadorow.html (accessed on: 2021-01-18).

97. WspólneProjekty BO 2020. PodgórzeDuchackie. Available online: https://www.facebook.com/groups/BO2020.XI.Podgorze.Duchackie (accessed on: 2021-01-18).

98. Archiwumprojektów. Available online: https://budzet.krakow.pl/229804,artykul,archiwum projektow.html(accessed on: 2021-01-18).

99. Clark, B. Y.; Zingale, N.; Logan, J. Intelligence and information gathering through deliberative crowdsourcing. Journal of Public and Nonprofit Affairs 2017, 3(1), 55-78. doi:10.20899/jpna.3.1.55-78.

100. Chikersal, P.; Tomprou, M.; Kim, Y. J.; Woolley, A.; Dabbish, L. Deep structures of collaboration: Physiological correlates of collective intelligence and group satisfaction. Proceedings of the 20th ACM Conference on Computer-Supported Cooperative Work and Social Computing (CSCW 2017).

101. Aggarwal, I.; Woolley, A.W.; Chabris, C.F.; Malone, T.W. The Impact of Cognitive Style Diversity on Implicit Learning in Teams. Front. Psychol. 2019, 10:112. doi: 10.3389/fpsyg.2019.00112.

102. Engel, D.; Malone, T.W. Integrated information as a metric for group interaction. PLoS ONE 2018 13(10): e0205335. https://doi.org/10.1371/journal.pone.0205335.

103. Yu, L.; Nickerson, J.V.; Sakamoto, Y. Collective Creativity: Where we are and where we might go. ArXiv2012, abs/1204.3890.

104. Bigham, J.; Bernstain, M.; Adar, E. Human-Computer Interaction and Collective Intelligence. In Handbook of Collective Intelligence. Malone, T., Bernstein, M. Eds., MIT University Press: Cambridge, MA, United States, 2015

105. Klein, M. Enabling Large-Scale Deliberation Using Attention-Mediation Metrics. Computer Supported Cooperative Work2011, doi: 10.2139/ssrn.1837707.

106. Rittel, H.W.J.; Noble, D. Issue-based information systems for design. Working Paper 492, Institute of Urban and Regional Development, University of California, Berkeley, 1989.

107. Klein, M., Towards Crowd-Scale Deliberation. Available online: https://ssrn.com/abstract=2987624 or http://dx.doi.org/10.2139/ssrn.2987624 (accessed on: 12-12-2020)

108. Skaržauskienè, A. Social Technologies and Collective Intelligence. MykolasRomeris University: Vilnius, Lithuania, 2015.

109. Vincenzo, I.; Giannoccaro, I.; Carbone, G.; Grigolini, P. Criticallity triggers the emergence of collective intelligence in groups. Physical Review E2017, 96, 022309.

110. Collins, B.J.; Marichal, J.; Neve, R. The social media commons: Public sphere, agonism, and algorithmic obligation, Journal of Information Technology \& Politics2020, doi: 10.1080/19331681.2020.1742266.

111. Becker, J.; Porter, E.; Centola, D. The wisdom of partisan crowds. Proceedings of the National Academy of Sciences 2019, 116(22):201817195, doi: 10.1073/pnas.1817195116.

112. Origgi, G. Designing Wisdom through the Web. In Collective WisdomLandemore, H., Elster, J. Eds.; Cambridge University Press: New York, United States, 2012.

113. Bonabeau, E. Decisions 2.0: The Power of Collective Intelligence. MIT Sloan Management Review2009, 50(2): 45-52.

114. Hardas M.S., Purvis L. Bayesian Vote Weighting in Crowdsourcing Systems. In: Nguyen NT., Hoang K., Jędrzejowicz P. (eds) Computational Collective Intelligence. Technologies and Applications. ICCCI 2012. Lecture Notes in Computer Science, vol 7653. Springer, Berlin, Heidelberg. https://doi.org/10.1007/978-3-642-34630-9 20.

115. Noveck, B.S. Smart Citizens, Smarter State The Technologies of Expertise and the Future of Governing, Harvard University Press: Cambridge, MA, United States, 2017.

116. Landemore, H. Collective Wisdom: Old and New. In Collective Wisdom, Landemore, H., Elster, J. Eds.; Cambridge University Press: New York, United States, 2012.

117. Salminen, J. Collective Intelligence in Humans: A Literature Review. arXiv2012, arXiv:1204.2991.

118. Hawkins, J. On Intelligence: How a New Understanding of the Brain Will Lead to the Creation of Truly Intelligent Machines. Times Books: New York, United States, 2004.

119. Habermas, J. The Theory of Communicative Action. Beacon Press, Boston, MA, United States, 1984.

120. Howe, J. Crowdsourcing: Why the power of the crowd is driving the future of business. Crown Business: New York, United States, 2008.

121. Beni, G.; Wang, J. Swarm Intelligence in Cellular Robotic Systems. Proceed. NATO Advanced Workshop on Robots and Biological Systems, Tuscany, Italy, June 26-30 (1989). Berlin, Heidelberg: Springer. pp. 703-712. doi:10.1007/978-3-642-58069-7_38.

122. Noveck, B.S. Crowdlaw: Collective Intelligence and Lawmaking. Analyse EKritik2018; 40(2): 359-380. 
123. Buecheler, T.; Sieg, J. H.; Füchslin, R. M.; Pfeifer, R. Crowdsourcing, Open Innovation and Collective Intelligence in the Scientific Method: A Research Agenda and Operational Framework, Proceedings of the Artificial Life XII -- Twelfth International Conference on the Synthesis and Simulation of Living Systems, Odense, Denmark, 19 August 2010 - 23 August 2010, 679-686. DOI: $10.5167 /$ uzh-42435.

124. Alvarez-Melgarejo, M.; Torres-Barreto, M. Resources and Capabilities from Their Very Outset: A Bibliometric Comparison between Scopus and the Web of Science. Review of European Studies 2018, volume 10 issue 4.

125. Singh, P., Piryani, R.; Singh, V.K.; Pinot, D. Revisiting subject classification in academic databases: A comparison of the classification accuracy of Web of Science, Scopus \& Dimensions. Journal of Intelligent $\mathcal{E}$ Fuzzy Systems 2020, volume 39 issue 2. 